\title{
APLIKASI PENGISIAN BAK AIR DAN KRAN OTOMATIS DENGAN MIKROKONTROLER
}

\author{
Oleh : \\ Ifni Joi, Tuti Anggraini \\ Staf Pengajar Jurusan Teknik Elektro Politeknik Negeri Padang \\ E-mail : ifnijoi@gmail.com
}

\begin{abstract}
At the last project had made System to fill t the Automaticc reservoir. This equipment used electrode sensor level such as cuprum which use to detection the high water. Out put $t$ his sensor will be proses by controller and controller give relay instruction to solenoid valve. If the water lack of the level, Controller will be active the valve antil the reservoir full, if the writer want the perfect equipment, the writer add the controller open close automatic valve. That worck is based on the distance of people to valve. If the distance of people near to valve, so the valve will open it self. As open loop controll system, valve use microcontroller AVR Atmega 8535 to Active the relay.
\end{abstract}

Keywords : Sensor Ultrasonic, Microcontrller AVR Atmega 8535, Relay, Selenoid valve

\section{PENDAHULUAN}

\section{Latar Belakang}

Dengan seiringan perkembangan zaman pada saat ini, kita dituntut untuk memahami perkembangan zaman. Dari pengamatan masih banyak masjid masjid yang menggunakan tangki atau bak air sebagai penampungan untuk berwudhu. Sebagian besar masjid masjid masih menggunakan pompa air yang dialiri ke bak atau tangki. Pada saat pengisian air banyak garin masjid yang lupa mematikan pompa air apabila bak atau tangki melimpah. Oleh sebab itu maka dirancanglah sebuah alat otomatis pengisian air dengan tujuan air tidak melimpah dan mempertahankan air tidak habis.

Alat ini menggunakan sensor level yang digunakan untuk mendeteksi ketinggian air. Output dari sensor ini akan diproses oleh kontroller dan kontroller akan mengaktifkan relay untuk memutuskan tegangan agar kran / solenoid tertutup. Apabila air berkurang dari level yang telah ditentukan maka kontroller akan memberi perintah untuk mengaktifkan relay agar kran terbuka.

Oleh sebab itu penulis membuat dan merancang suatu alat untuk pengisian bak air secara otomatis. Agar alat ini lebih sempurna maka penulis juga menambahkan pengontrolan buka tutup kran secara otomatis yang diaplikasikan pada kran masjid untuk berwudhu. Kinerjanya adalah berdasarkan jarak orang dengan kran. Apabila jarak orang dengan kran dekat maka kran terbuka sendiri. Dengan tambahan aplikasi ini maka penulis mengangkat sebuah judul sebagai tugas akhir yang berjudul "Aplikasi Pengisian Bak air dan kran otomatis". Pada pembuatan alat ini penulis menggunakan dua sensor yaitu sensor level (elektroda) dan sensor jarak (ping). 


\section{Tujuan}

Tujuan dari pembuatan alat ini adalah sebagai berikut:

$>$ Membuat perancangan alat pengontrolan kran yang dapat mengisi bak secara otomatis.

Membuat perancangan alat yang dapat mengendalikan kran air secara otomatis yang dapat di terapkan untuk kran wudhu.

\section{Batasan Masalah}

Perlu diberikan beberapa batasan permasalahan dengan tujuan agar pembahasan tidak meluas dan menyimpang dari tujuan pembuatan alat ini. Adapun batasan permasalahan dari sistem yang dirancang ini adalah :

- Sistem ini dirancang dengan kendali sensor elektroda sebagai pengaktifan kran secara otomatis.

- Sistem ini juga menggunakan sensor ultrasonik (ping) untuk mengukur jarak objek.

\section{LANDASAN TEORI}

\section{Power Supply(Catu Daya)}

Perangkat elektronika mestinya dicatu oleh suplai arus searah DC (direct current) yang stabil agar dapat bekerja dengan baik. Baterai atau accu adalah sumber catu daya DC yang paling baik. Namun untuk aplikasi yang membutuhkan catu daya lebih besar, sumber dari baterai tidak cukup. Sumber catu daya yang besar adalah sumber bolak-balik AC (alternating current) dari pembangkit tenaga listrik. Untuk itu diperlukan suatu perangkat catu daya yang dapat mengubah arus AC menjadi DC yaitu power supply (Catu Daya).

Catu daya tersusun oleh transformator, penyearah, kapasitor sebagai filter dan regulator. Tegangan bolak balik diturunkan nilainya oleh tranformator kemudian disearahkan dengan rangkaian dioda dan gelombang outputnya diratakan dengan kapasitor. Setelah diratakan oleh kapasitor, kemudian tegangan tersebut distabilkan oleh komponen peregulasi tegangan.

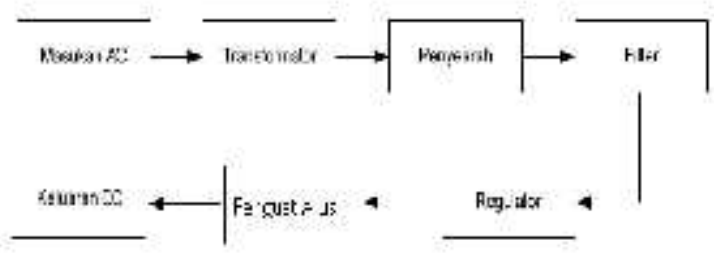

\section{Gambar 2.1. Diagram Blok Catu Daya}

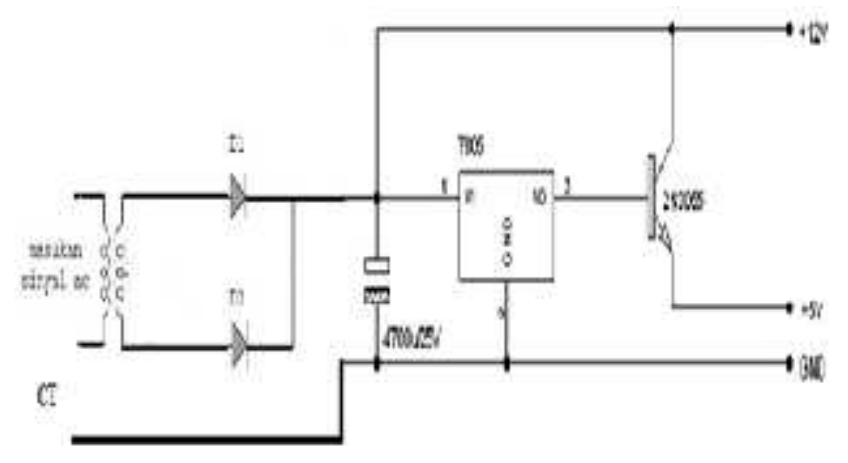

Gambar 2.2. Rangkaian Catu Daya Secara Umum

\section{Mikrokontroler AVR ATmega 8535}

Keunggulan yang ditawarkan oleh mikrokontroler AVR adalah eksekusi program yang cepat yaitu sebagian besar program dieksekusi dalam satu siklus clock, lebih cepat dibandingkan dengan mikrokontroler keluarga MCS-51 yang membutuhkan dua belas siklus clock untuk mengeksekusi satu instruksi. Hal ini dikarenakan mikrokontroler keluarga MCS-51 masih menggunakan teknologi CISC (Complex Instruction Set Compute) sebagai arsitekturnya. Selain kecepatan, mikrokontroler AVR sebagian besar telah dilengkapi dengan ADC internal, EEPROM internal, Watchdog Timer, PWM internal, komunikasi serial, I2C 
internal, Analog Comparator, Timer/Counter, Port I/O, dll. Dengan banyaknya fitur internal yang ditawarkan memudahkan perancangan elektronika karena programmer tidak disibukkan oleh banyaknya rangkaian dan pemasangan instalasi. Programmer hanya membuat settingan hardware melalui program saja sehingga banyaknya rangkaian dan pengkabelan dapat dikurangi.

\section{Konfigurasi Pin ATmega8535}

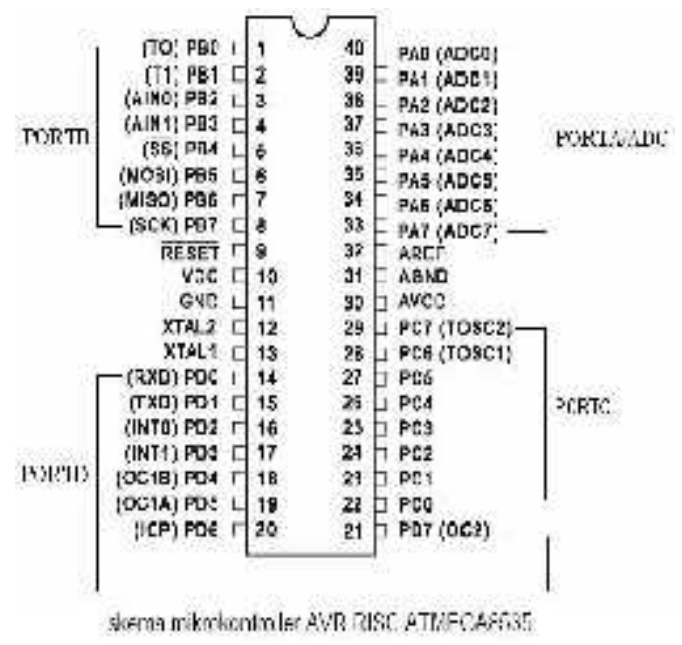

\section{Gambar 2.8. Konfigurasi pin ATmega8535}

1. VCC merupakan pin yang berfungsi sebagai pin masukan catu daya.

2. GND merupakan pin ground.

3. Port A (PA0..PA7) merupakan pin I/O dua arah dan pin input ADC.

4. Port B (PB0..PB7) merupakan pin $\mathrm{I} / \mathrm{O}$ dua arah dan pin fungsi khusus untuk Timer/Counter, Komparator analog, dan SPI.

5. Port C (PC0..PC7) merupakan pin I/O dua arah dan pin khusus untuk TWI, Komparator analog, dan Timer Oscilator.

6. Port D (PD0..PD7) merupakan pin I/O dua arah dan pin khusus untuk Komparator analog, Interupsi eksternal, dan Komunikasi serial.
7. RESET merupakan pin yang digunakan untuk me-reset mikrokontroller.

8. XTAL1 dan XTAL2 merupakan pin masukan clock eksternal.

9. AVCC merupakan pin masukan tegangan untuk ADC.

10. AREF merupakan pin masukan tegangan referensi ADC.

\section{Sensor Ping (Ultrasonik)}

Sensor jarak ultrasonik ping adalah sensor $40 \mathrm{khz}$ produksi parallax yang banyak digunakan untuk aplikasi atau kontes robot cerdas. Kelebihan sensor ini adalah hanya membutuhkan 1 sinyal ( SIG ) selain jalur $5 \mathrm{v}$ dan ground. Perhatikan gambar dibawah ini :

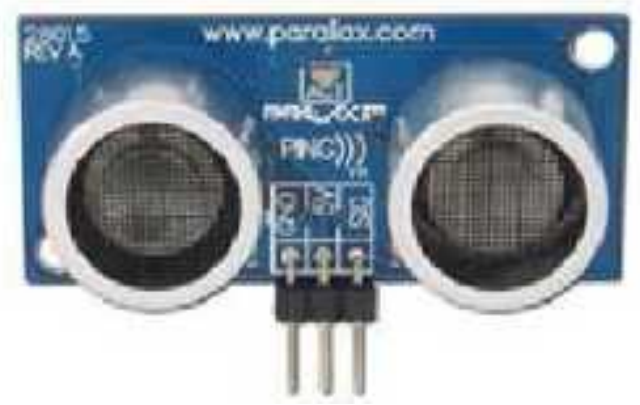

\section{Gambar 2.12 Sensor jarak ultrasonik ping}

Sensor Ping mendeteksi jarak obyek dengan cara memancarkan gelombang ultrasonik $(40 \mathrm{kHz})$ selama tBURST (200 s) kemudian mendeteksi pantulannya. Sensor Ping memancarkan gelombang ultrasonik sesuai dengan kontrol dari mikrokontroler pengendali (pulsa trigger dengan tOUT min. $2 \mathrm{~s}$ ). Gelombang ultrasonik ini melalui udara dengan kecepatan 344 meter per detik, mengenai obyek dan memantul kembali ke sensor. Ping mengeluarkan pulsa output high pada pin SIG setelah memancarkan gelombang ultrasonik dan setelah gelombang pantulan terdeteksi Ping akan membuat output low pada pin 
SIG. Lebar pulsa High (tIN) akan sesuai dengan lama waktu tempuh gelombang ultrasonik untuk 2x jarak ukur dengan obyek. Maka jarak yang diukur adalah [(tIN s x $344 \mathrm{~m} / \mathrm{s}) \div 2]$ meter.

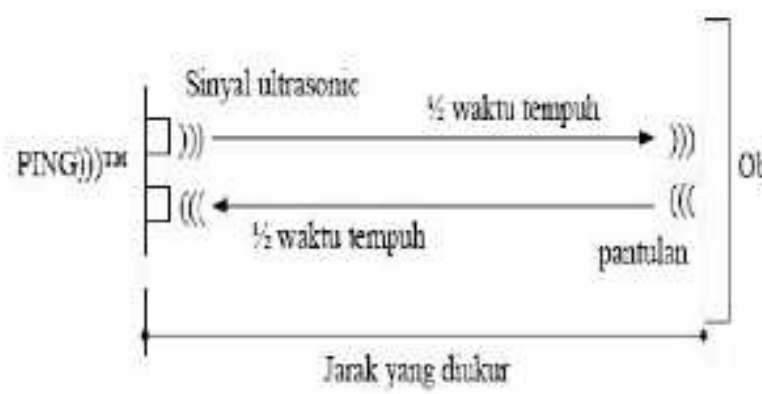

\section{Gambar 2.15 Jarak Ukur Sensor Ping}

Sistem minimal mikrokontroller ATMega 8535 dan software basic stamp Editor diperlukan untuk memprogram mikrokontroller dan mencoba sensor ini. Keluaran dari pin SIG ini yang dihubungkan ke salah satu port di kit mikrokontroller. Contoh aplikasi sensor PING pada mikrokontroler BS2, dimana pin SIG terhubung ke pa pin7, dan memberikan catu daya $5 \mathrm{~V}$ dan ground. fungsi Sigout untuk mentrigger ping, sedangkan fungsi Sigin digunakan untuk mengukur pulsa yang sesuai dengan jarak dari objek target.

\section{Relay}

Dalam dunia elektronika, relay

Pada gambar 2.16 Di bawah ini yaitu contoh relay yang beredar di pasaran:

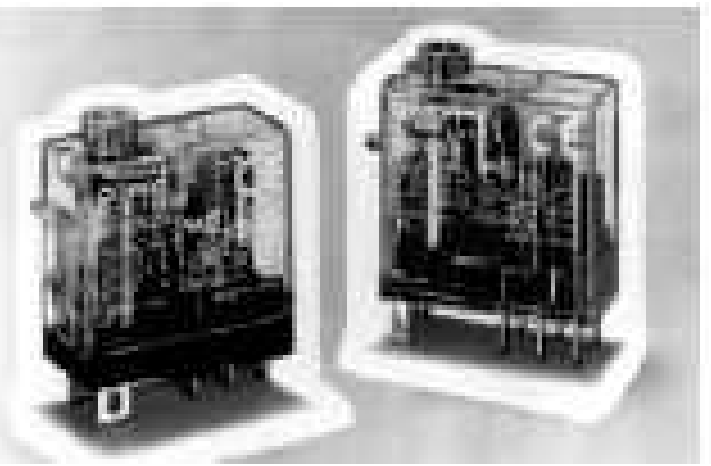

\section{Gambar 2.16 Relay yang tersedia di pasaran}

Secara umum, relay digunakan untuk memenuhi fungsi - fungsi berikut:

Remote control : dapat menyalakan atau mematikan alat dari jarak jauh.

Penguatan daya : menguatkan arus atau tegangan.

Contoh : starting relay pada mesin mobil.Pengatur logika kontrol suatu sistem.

\section{Prinsip Kerja Relay}

Relay terdiri dari coil dan contact. Perhatikan gambar 2.2, coil adalah gulungan kawat yang mendapat arus listrik, sedang contact adalah sejenis saklar yang pergerakannya tergantung dari ada tidaknya arus listrik di coil. Contact ada 2 jenis : Normally Open (kondisi awal sebelum diaktifkan open), dan Normally Closed (kondisi awal sebelum diaktifkan close).

Secara sederhana berikut ini prinsip kerja dari relay : ketika Coil mendapat energi listrik (energized), akan timbul gaya elektromagnet yang akan menarik armature yang berpegas, dan contact akan menutup. Untuk skema relay elektromekanik dapat kita lihat pada gambar 2.16 di bawah:

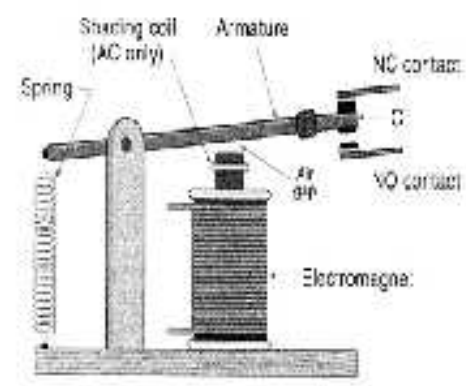

(a) Parts ot the relay

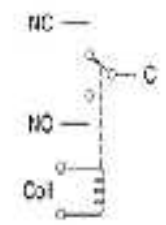

(b) h torminin tehametic syobol
Gambar 2.17 Skema relay elektromekanik

Modul LCD (Liquid Crystal Display) 


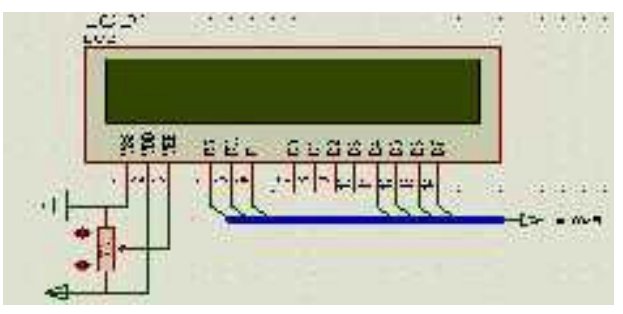

Gambar 2.21 Skema Rangkaian LCD Ke Microcontroller

LCD yang digunakan adalah jenis LCD M1632 yang merupakan modul LCD dengan tampilan 16 x 2 baris dengan konsumsi daya rendah. Modul tersebut dilengkapi dengan desain mikrokontroler yang didesain khusus untuk mengendalikan LCD. Mikrokontroler HD44780 buatan Hitachi yang berfungsi sebagai pengendali LCD memiliki CGROM, CGRAM, dan DDRAM. Berikut bagian-bagian dari LCD M1632.

1. DDRAM (Display data Random Accsee Memory) merupakan memori tempat karakter yang ditampilkan berada. Contoh untuk karakter ' $\mathrm{L}$ ' atau $4 \mathrm{CH}$ yang ditulis pada alamat 00 , karakter tersebut akan tampil pada baris pertama dan kolom pertama dari LCD. Apabila karakter tersebut ditulis pada alamat 40, maka karakter tersebut akan tampil pada baris kedua kolom pertama dari LCD.

2 CDRAM (Character Generator Random Acces Memory) merupakan memori untuk mengga,barkan pola sebuah karakter dimana bentuk dari karakter dapat diubah-ubah sesuai keinginan. Namun, memori akan hilang saat power supply tidak aktif sehingga pola karakter akan hilang.

3 CGROM (Character Generator Read Only Memory) merupakan memori untuk menggambarkan pola sebuah karakter dimana pola tersebut sudah ditentukan secara permanent dari HD44780 sehingga pengguna tidak dapat mengubahnya lagi. Namun, oleh karena ROM bersifat permanent, pola karakter tersebut tidak akan hilang walaupun power supply tidak aktif.

\section{Katup Listrik / Solenoid valve}

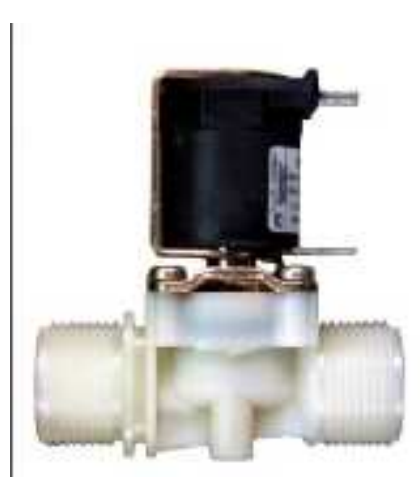

\section{Gambar 2.23 Solenoid Valve}

Katup Listrik / Solenoid valve atau sv adalah katup yang digerakan oleh energi listrik, mempunyai koil sebagai penggeraknya yang berfungsi untuk menggerakan piston yang dapat digerakan oleh arus AC maupun DC, sv mempunyai lubang keluaran, lubang masukan dan lubang exhaust, lubang masukan diberi kode $\mathrm{P}$, berfungsi sebagai terminal / tempat udara masuk atau supply, lalu lubang keluaran, diberi kode A dan B, berfungsi sebagai terminal atau tempat udara keluar yang dihubungkan ke beban, sedangkan lubang exhaust diberi kode $\mathrm{R}$, berfungsi sebagai saluran untuk mengeluarkan udara terjebak saat piston bergerak atau pindah posisi ketika sv ditenagai atau bekerja.

\section{Cara Kerja Selenoid}

Solenoid valve adalah salah satu alat atau komponen kontrol yang salah satu 
kegunaannya yaitu untuk menggerakan tabung cylinder, sv adalah katup listrik yang mempunyai koil sebagai penggeraknya yang mana ketika koil mendapat supply tegangan maka koil tersebut akan berubah menjadi medan magnet sehingga menggerakan piston pada bagian dalamnya ketika piston berpindah posisi maka pada lubang keluaran A atau B dari sv akan keluar udara yang berasal dari $\mathrm{P}$ atau supply, pada umumnya sv mempunyai tegangan kerja 100/200 VAC namun ada juga yang mempunyai

\section{PERANCANGAN DAN}

\section{PEMBUATAN}

\section{Perancangan Sistem}

Perancangan sistem meliputi hal-hal yang berhubungan dengan diagram blok, perancangans hardware, perancangan software dan perancangan papan rangkaian tercetak (PCB).

\section{Perancangan Hardware}

\section{Blok diagram}

Perancangan hardware secara umum dari "Aplikasi Pengisian Bak Air dan Kran Otomstis" ini dapat dilihat pada blok diagram di bawah ini:

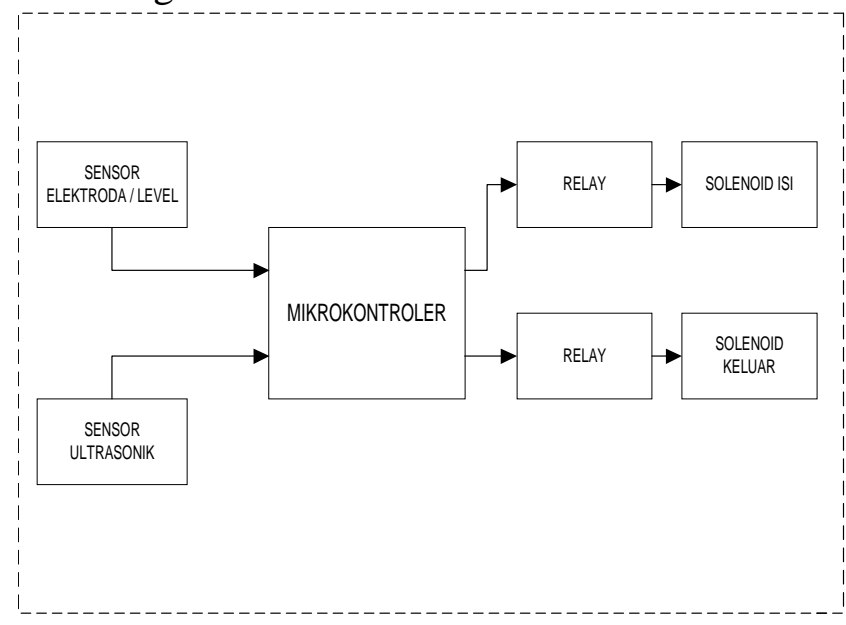

Gambar 3.1 Blok Diagram System
Pengontrol utama dari sistem pengisian bak dan kran otomatis ini adalah Mikrokontroler AVR ATMEGA8535. Mikrokontroler ini memiliki input dan output yang dapat mengendalikan dan membaca kondisi dari komponen/peralatan elektronika. Dalam system ini digunakan input berupa sensor level atau elektroda dan sensor ultrasonik / jarak (ping) dan outputnya berupa relay yang berfungsi mengaktifkn solenoid atau kran yang digunakan untuk pengisian bak dan kran otomatis. Pengontorlan relay diatur oleh mikrokontroler yang memberi perintah untuk relay on atau off.

c. Rangkaian Keseluruhan

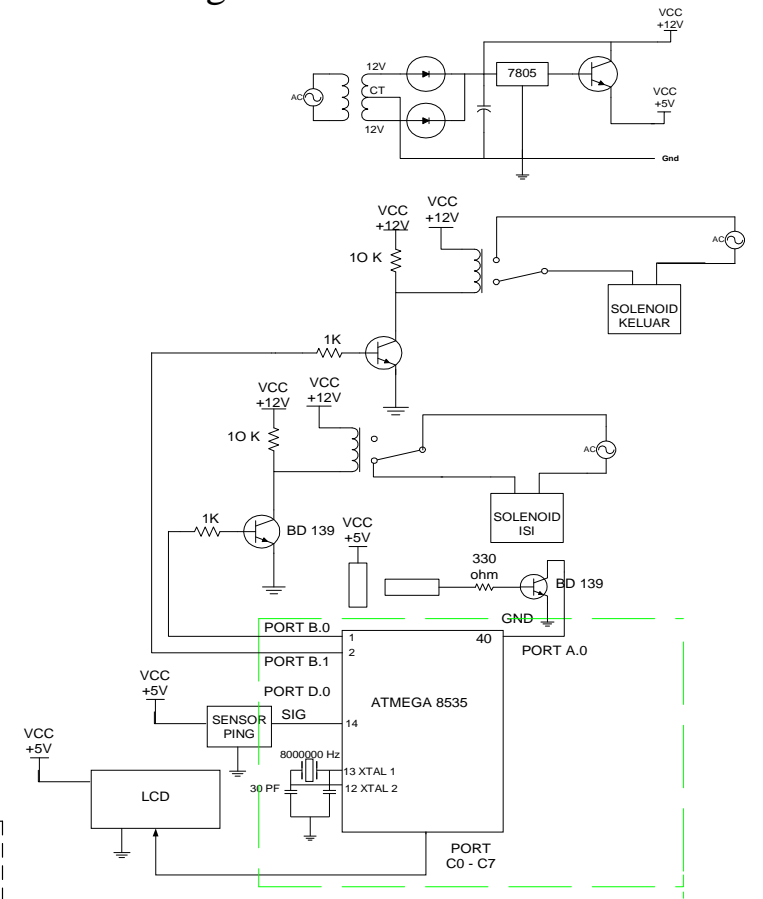

Gambar 3.8 Rangkaian System

Pengisian Bak dan Kran Otomatis

Perancangan Software

Perancangan alat pengontrontrolan ini berfungsi untuk mengontrol buka tutup kran secara otomatis yang digunakan untuk pengisisan bak air sesuai dengan perintah dari mikrokontroler. Dimana pada saat level air pada bak kurang dari set point pada sensor air maka mikrokontroler akan memberi perintah 
pada motor untuk membuka kran, dan jika level air telah mencapai setpoint pada sensor air maka kran otomatis akan tertutup. Untuk lebih mudah dipahami pada Gambar 3.12 berikut adalah gambar flowchart sistem dari perancangan software:

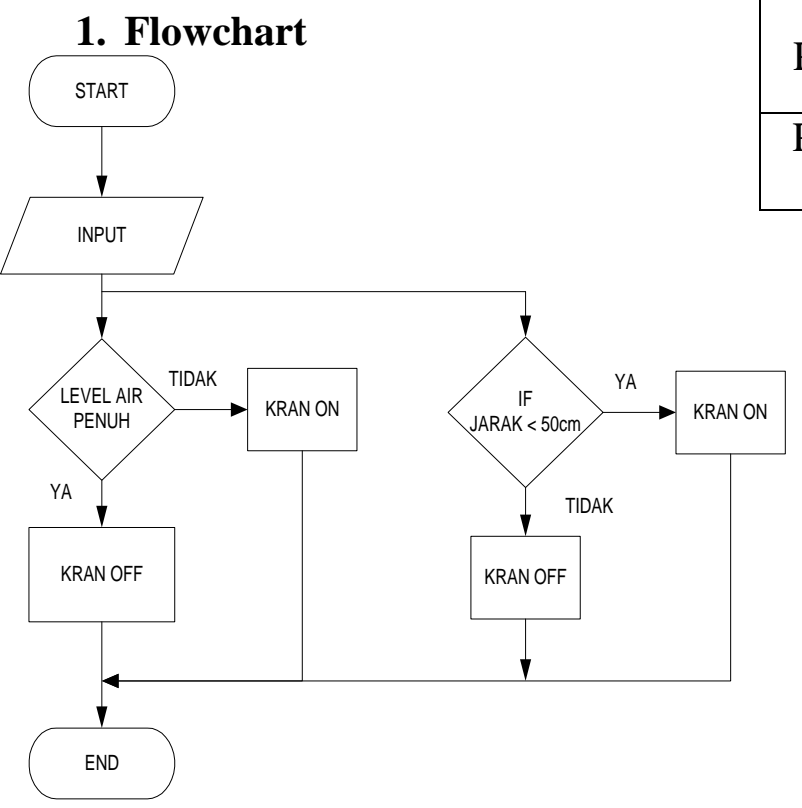

Gambar 3.9 Flowchart Sistem

2. Sistem

Mikrokontroller

Mikrokontroler dipergunakan untuk mengontrol system dengan acuan pembacaan data tegangan dari sensor level dan sebagai pengolah data dari sensor level. Pembacaan dari sensor berupa level tegangan yang kemudian di inputkan ke mikrokontroler kemudian diproses dan dioutputkan lagi dalam bentuk putaran motor yang akan membuka kran air.

Berikut ini merupakan pemakaian Port pada mikrokontroller.
Tabel 3.1. Tabel Input/Output Mikro

\begin{tabular}{|c|c|c|}
\hline PORT & $\begin{array}{c}\text { INPUT/OUTPU } \\
\text { T }\end{array}$ & $\begin{array}{c}\text { KETERANGA } \\
\text { N }\end{array}$ \\
\hline $\begin{array}{c}\text { PORT A.0 } \\
\text { PORT A.1 } \\
\text { PORT A.3 }\end{array}$ & INPUT & $\begin{array}{c}\text { Data Sensor } \\
\text { Eleketroda }\end{array}$ \\
\hline $\begin{array}{c}\text { PORT B.0- } \\
\text { B.7 }\end{array}$ & OUTPUT & Solenoid / kran \\
\hline $\begin{array}{c}\text { PORT D.0 } \\
\text { INPUT }\end{array}$ & $\begin{array}{c}\text { Data Sensor } \\
\text { Ultrasonik }\end{array}$ \\
\hline $\begin{array}{c}\text { PORT C0- } \\
\text { C7 }\end{array}$ & OUTPUT & LCD \\
\hline
\end{tabular}

\section{Pembuatan Program}

Untuk pembuatan program control alat ini, penulis menggunakan software Bascom AVR. Software ini dapat digunakan untuk pembuatan program control bagi mikrokontroller keluarga AVR dengan menggunakan bahasa basic.

\section{PENGUJIAN DAN ANALISA}

\section{Pengujian Sensor Ultrasonik (PING)}

- Bagaimana mengontrol kran secara otomatis dengan sensor ultrasonik(ping)?

Pada proses ini kran akan aktif jika sensor ultrasonik ( ping) terkena dengan benda atau objek dalam jarak yang telah ditentukan. Apabila objek menjauh dari jarak yang ditentukan maka kran akan mati.

Pengukuran pada sensor ping dilakukan secara manual dengan menggunakan penggaris atau meteran. Pengukuran dilakukan dari jarak $10 \mathrm{~cm}$ sampai $50 \mathrm{~cm}$. Berikut ini hasil tabel pengukuran pada sensor ping : 
Tabel 4.1 Data Sensor Ping

\begin{tabular}{|c|cc|}
\hline JARAK & $\begin{array}{r}\text { Waktu } \\
\text { tempuh }\end{array}$ \\
\hline $10 \mathrm{~cm}$ & 581,3953 & $\mathrm{~s}$ \\
$20 \mathrm{~cm}$ & 1162,7906 & $\mathrm{~s}$ \\
$30 \mathrm{~cm}$ & 1744,1860 & $\mathrm{~S}$ \\
$40 \mathrm{~cm}$ & 2325.5813 & $\mathrm{~s}$ \\
$50 \mathrm{~cm}$ & 2906,9767 & $\mathrm{~s}$ \\
& & \\
\hline
\end{tabular}

Dari hasil tabel diatas, bila jarak sensor dari $10 \mathrm{~cm}$ sampai $50 \mathrm{~cm}$ kran akan aktif karena pembacaan sensor telah dipogram apabila jarak objek atau benda dari sensor ultrasonik kurang dari $49 \mathrm{~cm}$ maka kran aktif. Jika jarak objek $>49 \mathrm{~cm}$ dari sensor maka kran akan mati.

Dari data tabel diatas dapat juga dicari nilai rata rata data sensor untuk per $1 \mathrm{~cm}$. Untuk mencari nilai rata rata data sensor untuk per $1 \mathrm{~cm}$ yaitu dengan menjumlahkan hasil rata rata waktu tempuh sensor dengan membaginya dengan jumlah data yang ada.

Untuk Nilai $1 \mathrm{~cm}=$ Jumlah Total waktu tempuh/ Jarak
Data $1=581,3953 / 10 \mathrm{~cm}$ $=58,3953$

Data $2=1162,7906 / 20 \mathrm{~cm}$ $=58,13953$

Data $3=1744,1860 / 30 \mathrm{~cm}$ $=58,139533$

Data $4=2325.5813 / 40 \mathrm{~cm}$ $=58,1395325$

Data $5=2906,9767 / 50 \mathrm{~cm}$ $=58,139534$

\section{Pengujian Sensor Elektroda}

Bagaimana merancang bangun sebuah pengisian bak air dengan mikrokontroller?

Pada perancangan pengisian bak air otomatis ini dikontrol oleh mikrokontroler yang mengatur relay untuk aktif atau tidaknya solenoid atau kran dengan sensor elektroda sebagai sensor level. Jika sensor level terkena air maka solenoid atau kran tersebut akan mati. Sebaliknya jika sensor level tidak terkena air maka solenid atau kran akan hidup sampai sensor terkena air kembali.

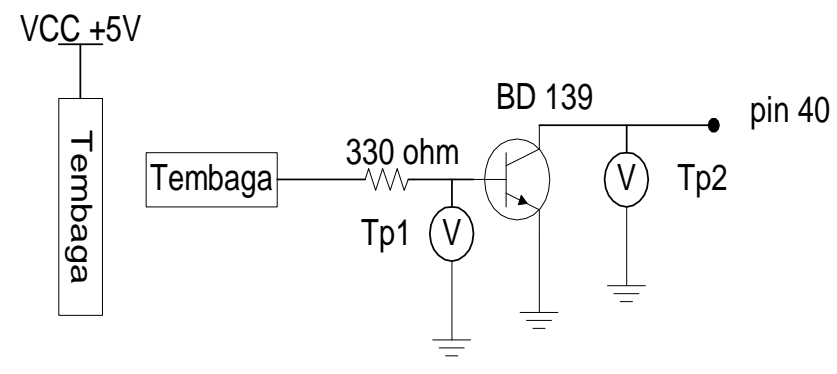

Gambar 4.2 Pengukuran pada Rangkaian Sensor Elektroda

Tabel 4.2 Pengukuran Pada rangkaian Sensor Elektroda

\begin{tabular}{|c|c|c|}
\hline VBE(TP1) & VCE(TP1) & STATUS \\
\hline $0.5 \mathrm{~V}$ & $0 \mathrm{~V}$ & PENUH \\
\hline $0 \mathrm{~V}$ & $3.6 \mathrm{~V}$ & KURANG \\
\hline
\end{tabular}

Pengujian sensor elektroda dilakukan untuk mengetahui tegangan input dari sensor ke mikrokontroller. output sensor ini tidak dapat langsung jadi input masukan untuk mikrokontroller, maka dibutuhkan transistor sebagai saklar agar dapat dijadikan input ke mikrokontroller. Tegangan yang masuk ke mikrokontroller adalah tegangan collector dari transistor. Apabila tegangan collector $0 \mathrm{~V}$ maka status air penuh dan solenoid tidak aktif atau kran air mati, sedangkan apabila tegangan collector 3,6 V maka status air kurang dan selenoid akan aktif atau kran air hidup.

\subsection{Pengujian Rangkaian Relay}




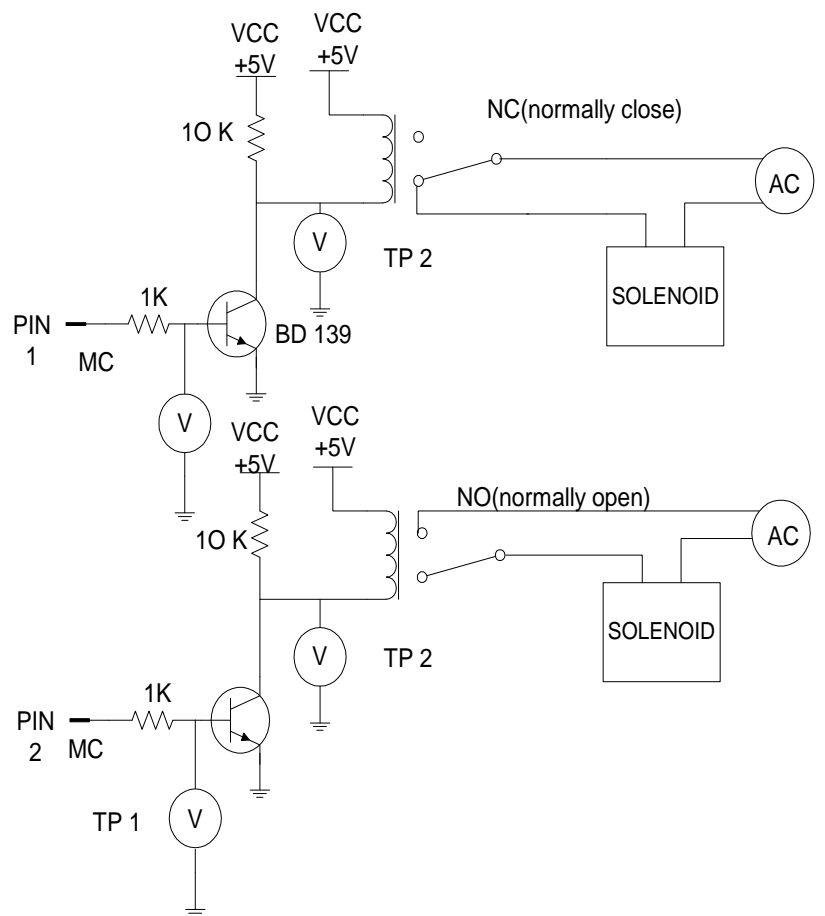

Gambar 4.4 Rangkaian Relay

Tabel 4.2 pengukuran pada rangkaian relay sensor PING (NormallyOpen)

\begin{tabular}{|c|c|c|c|}
\hline $\begin{array}{c}\text { VBE( } \\
\text { TP1) }\end{array}$ & $\begin{array}{c}\text { VCE(T } \\
\text { P2) }\end{array}$ & $\begin{array}{c}\text { Status } \\
\text { Relay }\end{array}$ & $\begin{array}{c}\text { Status } \\
\text { Kran }\end{array}$ \\
\hline $0.7 \mathrm{~V}$ & $0 \mathrm{~V}$ & Terhubung & $\begin{array}{c}\text { Kran } \\
\text { Buka }\end{array}$ \\
\hline 0 & $17 \mathrm{~V}$ & $\begin{array}{c}\text { Tidak } \\
\text { Terhubung }\end{array}$ & $\begin{array}{c}\text { Kran } \\
\text { Tutup }\end{array}$ \\
\hline
\end{tabular}

Kran otomatis akan aktif jika tegangan keluaran dari $\mathrm{MC}$ ke basis transistor berlogika 1 maka transistor akan aktif karena VCE bernilai 0 yang berarti transistor sebagai saklar tertutup dan relay akan aktif jika berlogika 0 . Pada saat $\mathrm{VBE}=0$ dan tegangan pada $\mathrm{VCE}=\mathrm{VCC}$, maka relay tidak aktif dan kran dalam keadaan tertutup.

Tabel 4.3 pengukuran pada rangkaian relay saat pengisian (Normally Close)

\begin{tabular}{|c|c|c|c|}
\hline $\begin{array}{c}\text { VBE( } \\
\text { TP1) }\end{array}$ & $\begin{array}{c}\text { VCE(T } \\
\text { P2) }\end{array}$ & $\begin{array}{c}\text { Status } \\
\text { Relay }\end{array}$ & $\begin{array}{c}\text { Status } \\
\text { Kran }\end{array}$ \\
\hline $0 \mathrm{~V}$ & $17 \mathrm{~V}$ & Terhubung & $\begin{array}{c}\text { Kran } \\
\text { Buka }\end{array}$ \\
\hline $0.7 \mathrm{~V}$ & 0 & $\begin{array}{c}\text { Tidak } \\
\text { Terhubung }\end{array}$ & $\begin{array}{c}\text { Kran } \\
\text { Tutup }\end{array}$ \\
\hline
\end{tabular}

Untuk rangkaian Relay pengisian bak, relay awalnya dalam keadaan tertutup(normally close) sehingga kran dalam keadaan terbuka.. Jika tegangan VBE mendekati $0.7 \mathrm{~V}$ dan VCE akan bernilai 0 sehingga relay akan aktif atau dalam keadaan terbuka sehingga kran akan tertutup karena tegangan pada kran dalam keadaan tidak terhubung.

\section{PENUTUP}

\section{Kesimpulan}

1. Hasil dari rata rata data sensor ping per $1 \mathrm{~cm}$ adalah 6.95 . Hasilnya didapat dari nilai data sensor dibagi dengan jarak.

2. Pada saat tembaga yang sebagai sensor elektroda terkena air maka tegangan yang terukur adalah 3.6v sebagai logika 1 .

\section{Saran}

Dari hasil penelitian ini, masih terdapat beberapa kekurangan yang dapat ditambahkan dalam proses penyempurnaan alat yang ada, dan yang dapat ditambahkan yaitu:

1. Bila ada menggunakan LCD, usahakan letaknya jauh dari komponen yang menghasilkan medan magnet supaya tidak terjadi error pada LCD.

2. Dengan beberapa pengembangan dan penyempurnaan sistem dari alat ini akan dapat lebih baik lagi hasilnya.

3. Hati hati dalam penggunakan komponen yang mempunyai sensitifitas tinggi, karena mudah 
terjadi kerusakan pada komponen tersebut.

\section{DAFTAR PUSTAKA}

Adi.wisnu.1972.mikrokontroller
ATMEGA

UGM:Yogyakarta

Malvino.Albert Paul.2003. PrinsipPrinsip Elekronika, buku satu, penerbit Salemba Teknika : Jakarta

Rusmadi.Dedy.1987.Pengenalan dasar elektronika, jilid 1,2,3. Sinar baru Del Fajar Utama:Bandung

Winoto.Ardi.2010.Mikrokontroler AVR ATMEGA8/32/16/8535 dan pemogramannya, edisi revisi, informatika : Bandung

www.atmel.com

$\underline{\text { www.datasheetcatalog.com }}$

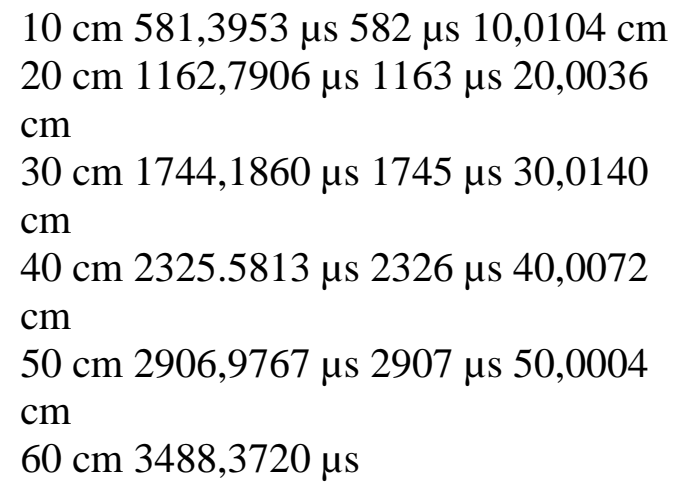

